\title{
Self-reported smoking cessation activities among Swiss primary
} care physicians

\author{
Isabelle Jacot Sadowski*1, Christiane Ruffieux ${ }^{2}$ and Jacques Cornuz ${ }^{1}$
}

Address: ${ }^{1}$ Department of Ambulatory Care and Community Medicine, University of Lausanne, Switzerland and ${ }^{2}$ Institute of Social and Preventive Medicine (IUMSP), University of Lausanne, Switzerland

Email: Isabelle Jacot Sadowski* - Isabelle.Jacot-Sadowski@chuv.ch; Christiane Ruffieux - Christiane.Ruffieux@chuv.ch; Jacques Cornuz - Jacques.Cornuz@chuv.ch

* Corresponding author

Published: 25 March 2009

BMC Family Practice 2009, 10:22 doi:10.1 186/1471-2296-10-22

This article is available from: http://www.biomedcentral.com/I47/-2296/I0/22

(C) 2009 Sadowski et al; licensee BioMed Central Ltd.

This is an Open Access article distributed under the terms of the Creative Commons Attribution License (http://creativecommons.org/licenses/by/2.0), which permits unrestricted use, distribution, and reproduction in any medium, provided the original work is properly cited.
Received: 18 November 2008

Accepted: 25 March 2009

\begin{abstract}
Background: Individual counselling, pharmacotherapy, and group therapy are evidence-based interventions that help patients stop smoking. Acupuncture, hypnosis, and relaxation have no demonstrated efficacy on smoking cessation, whereas self-help material may only have a small benefit. The purpose of this study is to assess physicians' current clinical practice regarding smokers motivated to stop smoking.

Methods: The survey included 3385 Swiss primary care physicians. Self-reported use of nine smoking cessation interventions was scored. One point was given for each positive answer about practicing interventions with demonstrated efficacy, i.e. nicotine replacement therapy, bupropion, counselling, group therapy, and smoking cessation specialist. No points were given for the recommendation of acupuncture, hypnosis, relaxation, and self-help material. Multivariable logistic analysis was performed to identify factors associated with a good practice score, defined as $\geq 2$.

Results: The response rate was 55\%. Respondents were predominately over the age of 40 years (88\%), male (79\%), and resided in urban areas (74\%). Seventeen percent reported being smokers. Most of the physicians prescribed nicotine replacement therapy (84\%), bupropion (65\%), or provided counselling (70\%). A minority of physicians recommended acupuncture $(26 \%)$, hypnosis (8\%), relaxation (7\%), or self-help material (24\%). A good practice score was obtained by $85 \%$ of respondents. Having attended a smoking cessation-training program was the only significant predictor of a good practice score (odds ratio: 6.24, 95\% Cl I.95-20.04).

Conclusion: The majority of respondents practice recommended smoking cessation interventions. However, there is room for improvement and implementing an evidence-based smoking cessation-training program could provide additional benefit.
\end{abstract}

\section{Background}

Physicians play an important role in smoking cessation, and medical advice and pharmacotherapy are effective clinical interventions to prompt and help patients to stop smoking [1-4]. Brief physician advice is effective for suc- cessful smoking cessation with odds ratio (OR) 1.66 (95\% CI 1.42 to 1.94 ) versus no advice or usual care [1]. The risk ratio (RR) of abstinence for any form of nicotine replacement therapy (NRT) relative to placebo or non-NRT group is 1.58 (95\% CI 1.50 to 1.66 ) [3]. Bupropion double the 
odds of cessation (OR 1.94, 95\% CI 1.72 to 2.19) [4] Group therapy is also effective (OR 2.19, 95\% CI 1.42 to 3.37 versus no intervention controls) whereas acupuncture, hypnosis, and autogenic training (relaxation technique with self-hypnosis) have no demonstrated efficacy on smoking cessation [2,5-7]. Self-help material such as brochures on tobacco and health might increase quit rates, but the size of the effect is small. Self-help materials have no additional benefit when used in concert with advice from a healthcare professional or with nicotine replacement therapy [8].

Around $80 \%$ of the Swiss general population visits a doctor annually, and most patients expect smoking cessation interventions from their physician [9-11]. Furthermore, studies have found clinical activities related to smoking cessation to be highly cost-effective in developed countries, particularly when compared to other currently accepted preventive activities, such as treating mild to moderate hypertension and lowering cholesterol levels [12].

However, some doctors perceive barriers to engaging in smoking cessation counselling, such as lack of patient interest, lack of confidence in their ability to discuss smoking cessation, lack of time, fear of harming the doctor-patient relationship and difficulty to advice smokers without smoking-related problems [13-16]. When practitioners are asked to judge the importance of different preventive activities in their clinical practice, 93\% judge controlling blood pressure to be "very important"; in contrast, only $73 \%$ find counselling on smoking cessation to be "very important" [13].

Physicians' own health habits, like sedentary lifestyle or drinking more than three alcoholic drinks per day, could also negatively influence their attitudes toward smoking cessation counselling (smoking status was not a predictor in this study) [13].

Surveys of Swiss patients have reported that $81 \%$ to $88 \%$ of smokers have discussed their smoking habits with a physician, but only $34 \%$ were advised to stop $[17,18]$.

In 2002, when the survey was conducted, the national program for smoking prevention 2001-2005 has just started (Federal Office of Public Health). An educational program to improve physicians' skills and effectiveness in smoking cessation has been developed and assessed by residents in outpatients clinics few years before [19]. Twenty-five teachers were trained in 2002 in order to disseminate the smoking cessation program nationwide. A reference manual on smoking cessation in clinical practice including algorithms for smokers approach and therapy, as well as patients' brochures were available. There were however hardly any smoking cessation specialists, except in few University hospitals.

When the survey took place, smoking cessation post-graduate training sessions were not uniformly implemented throughout Switzerland with linguistic regions difference: there were proportionally more training sessions in French-speaking region than in German part.

The purpose of this survey was to assess clinical practice of Swiss primary care physicians toward patients motivated to stop smoking. Our ultimate objective was to highlight areas in which tobacco prevention programs should focus their attention in order to enhance delivery of evidencebased clinical practice for promoting smoking cessation.

\section{Methods \\ Data collection}

Using the national registry of the Swiss primary care physicians, we randomly sampled $50 \%(n=1872)$ of the physicians in the German-speaking cantons, and included all of the physicians in the French-speaking $(n=1286)$ and Italian-speaking $(\mathrm{n}=227)$ regions. An invitation announcing the purpose of the survey and a copy of the questionnaire (with a self-addressed, pre-stamped envelope) were mailed to all 3385 doctors. Non-respondents received a single reminder letter eight weeks later that included a copy of the questionnaire. Data were processed anonymously.

The questionnaire was developed in French and 18 colleagues in Lausanne, Switzerland, conducted pilot testing. The instrument was professionally translated into German and Italian and checked for accuracy prior to study launch.

\section{Statistical analyses}

Univariate analyses were performed to describe the data. The multivariate model used one set of dichotomous data that combined information about the self-reported use of nine tobacco cessation interventions for smoking patients who wanted to quit, as described below.

For scoring the smoking cessation practice of physicians, one point was given for each positive answer about using the following evidence-based interventions: (a) prescription of nicotine replacement therapy, (b) prescription of bupropion, (c) direct smoking cessation counselling, (d) recommendation to attend group smoking cessation therapy, and (e) referral to a smoking cessation specialist for counselling. No points were added or deducted for the reported use of (a) acupuncture, (b) hypnosis, (c) relaxation techniques, or (d) written self-help material. Possible scores ranged from 0 to +5 . We predefined a dichotomous 
variable indicating a score $\geq 2$, to be interpreted as an indicator of good physician practice.

A multivariable logistic analysis was performed to identify factors favouring good physician practice. The following variables were considered: previously attending smoking cessation training, years since graduation (defined as $\leq 20$ years versus $>20$ years), urban residence, and smoking status (defined as daily smoker versus non-smoker including ex-smoker and occasional smoker). For this analysis, data were weighted according to the sample size. All statistical analyses were performed using Stata (StataCorp, College Station, TX, USA).

\section{Results}

Sample characteristics

1856 physicians, for a response rate of $54.8 \%$, returned the questionnaires. The response rates were $54.5 \%$, $54.8 \%$, and $57.7 \%$ for German-, French-, and Italianspeaking doctors, respectively $(\mathrm{p}=0.654)$.

Respondents were predominately 40 years of age or older $(88 \%)$, male $(79 \%)$, and practiced in urban areas $(74 \%)$. Over half of the sample came from the German-speaking area, a third from French-speaking regions, and less than a tenth of respondents were Swiss-Italian. The majority of respondents graduated between 11 and 30 years before to the survey, 5\% within the last 10 years of the survey, and $12 \%$ over 30 years before the survey. Only $5 \%$ of physicians had received training on smoking cessation counselling with significant linguistic difference (German:1.5\%,
French: $10.5 \%$, Italian: $3.2 \%, \mathrm{p}<0.001)$. Slightly over one-sixth reported being current daily or occasional smokers (Table 1).

Regarding physicians' choice of evidence-based smoking cessation interventions, the majority reported prescribing nicotine replacement therapy (84\%), bupropion (65\%), or providing an individual consultation to patients on their tobacco use $(70 \%)$. About one-third reported recommending participation in a smoking cessation group, and one-tenth referred smokers to a smoking cessation clinic (Table 2).

Regarding the unproven techniques, one-fourth of physicians recommended acupuncture and under one-tenth proposed hypnosis or relaxation techniques. Nearly, onefourth provided brochures on the topic.

Using the formulas described in the Methods section, $85 \%$ of physicians $(\mathrm{n}=1581)$ had a "good" score on tobacco cessation practices (Figure 1).

\section{Predictors of clinical tobacco cessation practices}

Our model for predicting characteristics of physicians with a "good" clinical practice score included having received smoking cessation training, having received their medical diploma more than 20 years prior to the survey, practicing in an urban environment, and personal smoking status. The language region (French, German, or Italian) was not included in the model because of its interaction with the availability of smoking cessation

Table I: Participants characteristics $(n=1856)$

\begin{tabular}{|c|c|c|}
\hline Variable & & $\%$ \\
\hline \multirow[t]{3}{*}{ Age } & $<40$ years & 12.0 \\
\hline & $40-49$ years & 39.3 \\
\hline & $>49$ years & 48.7 \\
\hline Male gender & & 78.8 \\
\hline \multirow[t]{3}{*}{ Linguistic region } & German & $55 \%$ \\
\hline & French & $38 \%$ \\
\hline & Italian & $7 \%$ \\
\hline Urban residence & & 73.6 \\
\hline \multirow[t]{4}{*}{ Years since graduation from medical school } & $0-10$ years & 4.7 \\
\hline & II-20 years & 32.0 \\
\hline & $21-30$ years & 51.6 \\
\hline & $30-40$ years & 11.7 \\
\hline Prior attending smoking cessation training & & 5.1 \\
\hline \multirow[t]{2}{*}{ Smoking status } & Daily smoker & 7.2 \\
\hline & Occasional smoker & 10.4 \\
\hline
\end{tabular}


Table 2: Physicians' self-reported use of smoking cessation interventions techniques for patients motivated to stop smoking ( $\mathrm{n}=\mathbf{I 8 5 3 )}$

\begin{tabular}{|c|c|c|}
\hline \multicolumn{2}{|c|}{ Physicians self-reported practices } & \multirow{2}{*}{$\begin{array}{l}\% \\
84.0\end{array}$} \\
\hline Demonstrated efficacy & Prescription of nicotine replacement therapy & \\
\hline & Prescription of bupropion & 65.4 \\
\hline & Personal consultation on patient's tobacco use & 70.1 \\
\hline & Recommendation to attend smoking cessation groups & 29.2 \\
\hline & Referral to a smoking cessation specialist & 9.6 \\
\hline \multirow[t]{4}{*}{ Efficacy not yet shown } & Acupuncture & 26.1 \\
\hline & Hypnosis & 7.9 \\
\hline & Relaxation & 7.4 \\
\hline & Brochures & 23.7 \\
\hline
\end{tabular}

courses for physicians, with less training sessions in the German part of Switzerland. Gender was not included in our model because this information was not needed to plan future programs.

Having received smoking cessation training was the only statistically significant predictor of a "good" clinical practice score (Table 3 ).

\section{Discussion}

The results of this survey suggest that the majority of Swiss primary care physicians practice evidence-based smoking cessation interventions. A large majority of these physicians reported prescribing first-line therapies including nicotine substitutes and bupropion, as well as providing individual counselling on how to quit using tobacco. Only a small minority reported recommending attending a smoking cessation group or referring smokers to tobacco specialists.

The only characteristic positively associated with a good practice score on smoking cessation intervention was hav-

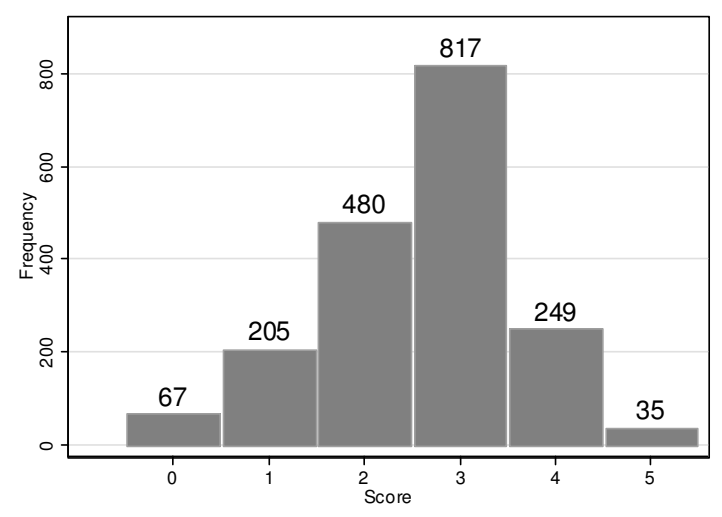

Figure I

Distribution of smoking cessation clinical practice scores of Swiss physicians $(n=$ I 853). ing attended smoking cessation training. Physicians' own smoking status was not significantly correlated with smoking cessation practices, as has been reported in other studies; however, an association between personal health behaviour and attitude toward health promotion has been reported $[13,20,21]$. The interval since physicians received their medical diplomas and whether or not they practiced in an urban environment were not significantly correlated with tobacco cessation interventions.

International studies have assessed physicians' incorporation of tobacco control interventions in their clinical practice and their opinions about national guidelines [22-25]. However, it was not possible to compare Swiss physician practices with this data because the questions in the surveys and the health systems are not similar.

Our study had some limitations. Firstly, our response rate $(55 \%)$ led us to question whether there was potential bias. However, this participation rate is in concordance with rates reported in other physician surveys [21-23]. Furthermore, response bias might not pose as much of a methodological challenge in this relatively homogenous population in terms of age and gender as compared to the general physician population, except the slight smaller proportion of respondents who were daily smokers, 7\% versus $12 \%$ reported in a previous survey [26]. Secondly, respondents were perhaps more motivated in this topic, that could have resulted in overestimation of the quality of the smoking cessations interventions. A third limitation was using the score variables to combine responses to multiple survey questions. These unvalidated measures could have led to bias in the regression analyses. Giving equal weighting to the interventions is an approximate way to establish the score, as recommending counselling is probably a weaker intervention than direct counselling.

Just self-reported attitude, no measure of frequency, no measure of whether physicians assessed smoking status and non-uniformly implementation of smoking cessation 
Table 3: Predictors of smoking cessation clinical practices: Multivariable logistic analysis.

\begin{tabular}{llll}
\hline Outcome & Predictor & $\begin{array}{l}\text { Odds ratio } \\
(95 \% \mathrm{Cl})\end{array}$ \\
\hline Good score & Prior attending smoking cessation training & $6.24(1.95,20.04)$ & 0.002 \\
& Graduation $>20$ years & $1.13(0.84,1.51)$ & 0.415 \\
& Urban residence & $0.75(0.54,1.06)$ & 0.103 \\
& Daily smoker & $0.87(0.51,1.48)$ & 0.597 \\
\hline
\end{tabular}

Adjusted odds ratio.

training sessions with linguistic difference are additional limitations.

We think there are important policy implications in improving the practice scores among physicians who had or had not previously taken a smoking cessation course. Although this survey did not measure clinical outcomes in patients, we assumed that patients being followed by physicians with better smoking cessation practice scores would have higher quit rates. Therefore, our data provide impetus for promoting more smoking cessation training courses for physicians. Further evidence of the benefits of training physicians can be found in a prior randomized controlled trial among physicians, in which patients assigned to doctors who received smoking cessation training had improved smoking-related behavioural and clinical outcomes [27].

Since this survey was conducted in 2002, the Swiss national program for tobacco prevention published clinical recommendations and organized smoking cessation training courses for physicians [28-31]. More than 4000 Swiss physicians have provided teaching assistance.

\section{Conclusion}

The majority of participating Swiss physicians practice recommended smoking cessation interventions with patients motivated to stop smoking. However, the number of physicians practicing these interventions could be increased and implementation of the interventions could be improved; smoking cessation training courses are an effective means of achieving both goals.

\section{Competing interests}

JC is member of the Swiss expert panel that promotes smoking cessation and is in charge of the Swiss physician smoking cessation-training program "Vivre sans tabac". IJS is collaborating in the Swiss physician smoking cessation-training program "Vivre sans tabac".

\section{Authors' contributions}

IJS participated to the interpretation of data and drafted the manuscript. CR participated to the study design and performed the statistical analysis. JC participated to the study design, interpretation of data and revised the man- uscript. All authors read and approved the final manuscript.

\section{Sources of funding for the study}

Department of Ambulatory Care and Community Medicine, Lausanne University Hospital, Switzerland. Institute of Social and Preventive Medicine (IUMSP), University of Lausanne, Switzerland.

\section{References}

I. Stead LF, Bergson G, Lancaster T: Physician advice for smoking cessation. Cochrane Database Syst Rev 2008:Article Nr.: CD000I65.

2. Fiore MC, Jaen CR, Baker TB, Bailey WC, Benowitz NL, Curry SJ, Dorfman SF, Froelicher ES, Goldstein MG, Healton CG, Nez Henderson P, Heyman RB, Koh HK, Kottke TE, Lando HA, Mecklenburg RE, Mermelstein RJ, Dolan Mullen P, Orleans CT, Robinson L, Stitzer ML, Tommasello AC, Villejo L, Wewers ME: Treating Tobacco Use and Dependence: Clinical Practice Guideline. 2008 Update. 2008 [http://www.ahrq.gov/path/tobacco.htm\#Clinic]. Agency for Health Care Policy and Research, Public Health Service, US Dept of Health and Human Services

3. Stead LF, Perera R, Bullen C, Mant D, Lancaster T: Nicotine replacement therapy for smoking cessation. Cochrane Database Syst Rev 2008:Art. Nr.: CD000146.

4. Hughes JR, Stead LF, Lancaster T: Antidepressants for smoking cessation. Cochrane Database Syst Rev 2007:Art. Nr.: CD00003I.

5. Stead LF, Lancaster T: Group behaviour therapy programmes for smoking cessation. Cochrane Database Syst Rev 2005:Art. Nr.: CD00I007.

6. White AR, Rampes $H$, Campbell JL: Acupuncture and related interventions for smoking cessation. Cochrane Database Syst Rev 2006:Art. Nr.: CD000009.

7. Abbot NC, Stead LF, White AR, Barnes J: Hypnotherapy for smoking cessation. Cochrane Database Syst Rev 1998:Art. Nr.: CD00I008.

8. Lancaster T, Stead LF: Self-help interventions for smoking cessation. Cochrane Database Syst Rev 2005:Art. Nr.: CD00III8.

9. Swiss Federal Office of Statistics: Enquête suisse sur la santé 2002 (Swiss Health Survey 2002). Neuchâtel; Swiss Federal Office of Statistics; 2003.

10. Humair JP, Sanchez-Menegez C, Stalder H: Prévention par les médecins de premier recours à Genève: Attitudes, habitudes personnelles et pratiques cliniques (Primary care physicians and prevention in Geneva: Attitudes, personal health behaviour and clinical practice). Zurich; Assemblée Annuelle de la Société Suisse de Médecine Interne 1996.

II. Conroy MB, Majchrzak NE, Regan S, Silverman CB, Schneider LI, Rigotti NA: The association between patient-reported receipt of tobacco intervention at a primary care visit and the smokers' satisfaction with their health care. Nicotine Tob Res 2005, 7:S29-S34.

12. Cornuz J, Pinget C, Gilbert A, Paccaud F: Cost-effectiveness analysis of the first-line therapies for nicotine dependence. Eur J Clin Pharmacol 2003, 59:20I-206.

13. Cornuz J, Ghali WA, Di Carlantonio D, Pecoud A, Paccaud F: Physicians' attitudes towards prevention: importance of intervention-specific barriers and physicians' health habits. Fam Pract 2000, 17:535-540. 
14. Vogt F, Hall S, Marteau TM: General practitioners' and family physicians' negative beliefs and attitudes toward discussing smoking cessation with patients: a systematic review. Addiction 2005, I00:|423-|43|.

15. McEwen $A$, West $R$, Preston A: Triggering anti-smoking advice by GPs: Mode of action of an intervention stimulating smoking cessation advice by GPs. Patient Educ Couns 2006, 62:89-94.

16. Wynn A, Coleman T, Barrett S, Wilson A: Factors associated with the provision of anti-smoking advice in general practice consultations. Br $\int$ Gen Pract 2002, 52:997-999.

17. Eckert $T$, Junker $C$ : Motivation for smoking cessation: what role do doctors play? Swiss Med Wkly 200I, I 31:52I-526.

18. Krebs H, Keller R, Hornung R: Prise en charge médicale des fumeurs en Suisse: opinion des fumeurs et anciens fumeurs. Résumé du rapport de recherche 2003. In Monitorage sur le tabac - Enquête suisse sur le tabagisme (Physicians'clinical practice toward smokers in Switzerland: smokers and ex-smokers opinion. Swiss Tobacco Monitoring Survey). Universität Zürich; 2006.

19. Humair JP, Cornuz J: A new curriculum using active learning methods and standardized patients to train residents in smoking cessation. J Gen Intern Med 2003, 18:1023-1027.

20. Steptoe A, Doherty S, Kendrick T, Rink E, Hilton S: Attitudes to cardiovascular health promotion among GPs and practice nurses. Fam Prac 1999, 16:158-163.

21. Brotons C, Björkelund C, Bulc M, Ciurana R, Godycki-Cwirko M, Jurgova E, Kloppe P, Lionis C, Mierzecki A, Pineiro R, Pullerits L, Sammut MR, Sheehan M, Tataradze R, Thireos EA, Vuchak J, EUROPREV Network: Prevention and health promotion in clinical practice: the views of general practitioners in Europe. Prev Med 2005, 40:595-60I.

22. Ward MM, Vaughn TE, Uden-Holman T, Doebbeling BN, Clarke WR, Woolson RF: Physician knowledge, attitudes and practices regarding a widely implemented guideline. J Eval Clin Pract 2002, 8: $155-162$

23. Kotz D, Wagena EJ, Wesseling G: Smoking cessation practices of Dutch general practitioners, cardiologists, and lung physicians. Respir Med 2007, 3:568-573.

24. Young JM, Ward JE: Implementing guidelines for smoking cessation advice in Australian general practice: opinions, current practices, readiness to change and perceived barriers. Fam Pract 200I, 18:14-20.

25. Mcllvain HE, Backer EL, Crabtree BF, Lacy N: Physician attitude and the Use of office-based activities for tobacco control. Fam Med 2002, 34: I I4-II 9.

26. Sebo P, Bouvier Gallacchi M, Goehring C, Kunzi B, Bovier PA: Use of tobacco and alcohol by Swiss primary care physicians: a cross-sectional survey. BMC Public Health 2007, I 2;7:5.

27. Cornuz J, Humair JP, Seematter L, Stoianov R, van Melle G, Stalder H, Pecoud A: Efficacy of resident training in smoking cessation: a randomized controlled trial of a program based on application of behavioral therapy and practice with standardized patients. Ann Intern Med 2002, 136:429-37.

28. Cornuz J, Humair JP, Zellweger JP: Désaccoutumance au tabac. lère partie: Processus de désaccoutumance et bénéfices de l'arrêt (Smoking cessation: Swiss clinical recommendations). Schweiz Med Forum 2004, 4:334-339.

29. Cornuz J, Humair JP, Zellweger JP: Désaccoutumance au tabac. 2ème partie: Recommandations pour la pratique clinique (Smoking cessation: Swiss clinical recommendations). Schweiz Med Forum 2004, 4:356-368.

30. Frei von Tabak [http://www.frei-von-tabak.ch]

31. Frei von Tabak [http://www.vivre-sans-tabac.ch]

\section{Pre-publication history}

The pre-publication history for this paper can be accessed here:

http://www.biomedcentral.com/1471-2296/10/22/pre pub
Publish with Biomed Central and every scientist can read your work free of charge

"BioMed Central will be the most significant development for disseminating the results of biomedical research in our lifetime. "

Sir Paul Nurse, Cancer Research UK

Your research papers will be:

- available free of charge to the entire biomedical community

- peer reviewed and published immediately upon acceptance

- cited in PubMed and archived on PubMed Central

- yours - you keep the copyright

Submit your manuscript here:

http://www.biomedcentral.com/info/publishing_adv.asp
BioMedcentral 